\title{
TRATAMENTOS PÓS-COLHEITA COM 1-METILCICLOPROPENO EM MANGA 'TOMMY ATKINS': EFEITO DE DOSES E NÚMERO DE APLICAÇÕES'
}

\author{
MARIA AUXILIADORA COÊLHO DE LIMA², ADRIANE LUCIANA DA SILVA3 \\ SUELLEN SORAIA NUNES AZEVEDO ${ }^{4}$, POLYANE DE SÁ SANTOS 5
}

\begin{abstract}
RESUMO - Foram conduzidos dois experimentos com o objetivo de avaliar a eficiência de tratamentos com 1-MCP sobre a conservação da manga 'Tommy Atkins', reconhecendo doses e número de aplicações. Os frutos foram colhidos no estádio de maturação 2, em pomar comercial localizado em Petrolina, Pernambuco. No primeiro experimento, foram testados: 1 . doses $\left(0 ; 600 ; 1.200\right.$ e $\left.2.400 \mathrm{~nL} \mathrm{~L}^{-1}\right)$, aplicadas a $25^{\circ} \mathrm{C}$; e 2 . tempo de armazenamento $(0 ; 2 ; 4 ; 7 ; 9 ; 10$ e 11 dias $)$, em temperatura ambiente $\left(26,7 \pm 2,0^{\circ} \mathrm{C}\right)$. O delineamento experimental foi o inteiramente casualizado, em fatorial 4 x 7 (doses de 1-MCP x tempo de armazenamento), com 4 repetições. No segundo experimento, foram estudados: 1 . doses e número de aplicações (controle, uma aplicação de $900 \mathrm{~nL} \mathrm{~L}^{-1}$, uma aplicação de $1.200 \mathrm{~nL} \mathrm{~L}^{-1}$ e duas aplicações de $900 \mathrm{~nL} \mathrm{~L}^{-1}$ ); e 2. tempo de armazenamento (0; $7 ; 15 ; 18 ; 20 ; 22 ; 25$ e 26 dias), sendo os frutos mantidos refrigerados $\left(11,0 \pm 1,6^{\circ} \mathrm{C}\right.$ e $88 \pm 7 \%$ UR) até o $15^{\circ}$ dia e, então, transferidos para temperatura ambiente $\left(26,3 \pm 2,1^{\circ} \mathrm{C}\right.$ e $44 \pm 6 \%$ UR). Neste experimento, o delineamento foi inteiramente casualizado, em fatorial 4 x 8 (dose e número de aplicações de 1-MCP x tempo de armazenamento), com 4 repetições. A primeira ou única aplicação ocorreu no dia da colheita e a segunda, no $14^{\circ}$ dia. $\mathrm{O} 1-\mathrm{MCP}$ afetou essencialmente a firmeza da polpa, sendo $1.200 \mathrm{~nL} \mathrm{~L}^{-1}$ a dose mais eficiente no retardo do amaciamento. A realização de uma aplicação de 1.200 $\mathrm{nL} \mathrm{L}^{-1}$ ou duas de $900 \mathrm{~nL} \mathrm{~L}^{-1}$, sob refrigeração, resultou em efeitos praticamente equivalentes. Porém, as alterações logísticas promovidas por uma única aplicação são menores.
\end{abstract}

Termos para Indexação: amadurecimento, firmeza da polpa, inibidores de etileno, vida útil.

\section{POSTHARVEST TREATMENTS WITH 1-METHYLCYCLOPROPENE IN 'TOMMY ATKINS' MANGO FRUIT: EFFECT OF DOSES AND NUMBER OF APPLICATIONS}

\begin{abstract}
Two experiments were carried out with the objective of evaluating the efficiency of treatments with 1-MCP on 'Tommy Atkins' mango fruit conservation, using different doses and number of applications. The fruits were harvested at the stage 2 of maturation from a commercial orchard in Petrolina, Pernambuco State, Brazil. In the first experiment, the following was tested: 1. doses $\left(0 ; 600 ; 1,200\right.$ and 2,400 nL L $\left.{ }^{-1}\right)$, applied at $25^{\circ} \mathrm{C}$; and 2 . storage time $(0,2,4,7,9,10$ and 11 days $)$ under room temperature $\left(26.7 \pm 2.0^{\circ} \mathrm{C}\right)$. The experimental design was completely randomized, with a 4 x 7 (doses of 1-MCP x storage time) factorial and 4 replicates. In the second experiment, the following was studied: 1 . doses and number of applications (control, one application of $900 \mathrm{~nL} \mathrm{~L}^{-1}$, one application of 1,200 $\mathrm{nL} \mathrm{L}^{-1}$ and two applications of $\left.900 \mathrm{~nL} \mathrm{~L}^{-1}\right)$; and 2. storage time $(0,7$, 15, $18,20,22,25$ and 26 days), being the fruits kept refrigerated $\left(11.0 \pm 1.6^{\circ} \mathrm{C}\right.$ and $\left.88 \pm 7 \% \mathrm{RH}\right)$ until the $15^{\text {th }}$ day, when they were transferred to room temperature $\left(26.3 \pm 2.1^{\circ} \mathrm{C}\right.$ and $\left.44 \pm 6 \% \mathrm{RH}\right)$. The first or single application occurred at the harvest time and the second one occurred at the $14^{\text {th }}$ day. In this experiment, the experimental design was completely randomized, with a 4 x 8 (doses and number of applications of 1-MCP x storage time) factorial and 4 replicates. 1-MCP affected essentially the pulp firmness and the most efficient dose in retarding of softening was $1,200 \mathrm{~nL} \mathrm{~L}^{-1}$. The accomplishment of one application of $1,200 \mathrm{~nL} \mathrm{~L}^{-1}$ or two applications of $900 \mathrm{~nL} \mathrm{~L}^{-1}$ under refrigeration had in practice the same effects. However, the logistics changes promoted by a single application are reduced.
\end{abstract}

Index Terms: ripening, pulp firmness, ethylene inhibitors, storage life.

\section{INTRODUÇÃO}

A produção de manga no Nordeste do Brasil alcançou uma área de 40.529 ha, em 2003, que representa cerca de $59 \%$ do total nacional (IBGE, 2005). Dessa produção, uma parcela significativa destina-se ao mercado exterior. Em 2004, de 111.181 t de mangas exportadas pelo Brasil, 92\% foram produzidas nos Estados de Pernambuco e da Bahia, especificamente na Região do Submédio São Francisco (VALEXPORT, 2005).

Apesar de o volume de manga exportado por essa região representar $35 \%$ de sua produção total, é essencial que se invista em qualidade para que se obtenham frutos de maior valor comercial. Essa valorização é requisito para que o Brasil consolide sua posição de principal exportador de manga para a Europa, aumente sua participação no mercado americano e atinja o recém-aberto mercado asiático. Um dos meios mais seguros para alcançar esse fim é a utilização de técnicas de conservação que prolonguem a vida útil pós-colheita.

Considerando que a via marítima é a mais utilizada e barata para a exportação da manga e que a vida útil desta fruta é limitada, é imprescindível desenvolver métodos de conservação mais eficientes e adequados à realidade dos mercados. Além da refrigeração, outras tecnologias podem ser implementadas visando a retardar o amadurecimento. O uso de inibidores da ação de etileno, como 1metilciclopropeno (1-MCP), pode ser uma ferramenta útil.

O 1-MCP tem sido estudado com o objetivo de retardar o amadurecimento de frutos climatéricos. Resultados experimentais ressaltam sua eficiência em estender a vida útil de maçã (Argenta et al., 2001), ameixa (Dong et al., 2002), banana (Harris et al., 2000) e damasco (Fan et al., 2000), entre outros. As respostas dependem, em geral, da concentração e do tempo de exposição ao gás, mas variam com a espécie, a cultivar, o estádio de maturação e as condições de armazenamento (Sisler \& Serek, 1997; Harris et al., 2000).

Em manga 'Tommy Atkins', Alves et al. (2004) estudaram os efeitos da aplicação do 1-MCP em frutos colhidos em estádio 2 de maturação e concluíram que a dose de $120 \mathrm{~nL} \mathrm{~L}^{-1}$ retardou o pico climatérico e reduziu a taxa respiratória, a evolução da cor da casca e a perda de massa, mantendo maiores a firmeza da polpa e a acidez titulável. No entanto, o atraso no amadurecimento foi de apenas dois dias. Outros autores encontraram respostas variadas a partir de aplicações de $100 \mathrm{e}$ $500 \mathrm{~nL} \mathrm{~L}^{-1}$ (Cocozza, 2003; Cocozza et al., 2004). Portanto, os estudos realizados até o momento indicam que uma possível recomendação para manga depende da melhor compreensão da técnica no que diz respeito à sua interferência no metabolismo do fruto. Entendidos estes efeitos, há de se ajustar doses e procedimentos de aplicação.

\footnotetext{
${ }^{1}$ (Trabalho 038/2005). Recebido: 04/03/2005. Aceito para publicação: 23/02/2006.

${ }^{2}$ Dra., Pesquisadora, Embrapa Semi-Árido, BR 428, Km 152, Caixa Postal 23, 56.302-970, Petrolina-PE. E-mail: maclima@cpatsa.embrapa.br

${ }^{3}$ B.Sc., Tecnóloga em Alimentos, Bolsista FAGRO/Rohm and Haas Química Ltda.

${ }^{4}$ Graduando em Biologia, Universidade de Pernambuco (UPE)/Faculdade de Formação de Professores de Petrolina (FFPP), Bolsista PIBIC-FACEPE/CNPq

${ }^{5}$ Graduando em Biologia, UPE/FFPP, Bolsista PIBIC/CNPq
} 
O objetivo deste estudo foi avaliar a eficiência de tratamentos pós-colheita com 1-MCP (SmartFresh ${ }^{\mathrm{TM}}, 0,14 \%$ i.a.) sobre a vida útil da manga 'Tommy Atkins', reconhecendo doses e número de aplicações mais indicados.

\section{MATERIAL E MÉTODOS}

Foram conduzidos dois experimentos, utilizando-se de mangas 'Tommy Atkins' colhidas em estádio de maturação 2 (casca de cor verdeclara no ápice do fruto e polpa levemente amarela próximo à semente), provenientes de área de produção comercial, em Petrolina-PE. Após a colheita, os frutos foram selecionados, considerando-se uniformidade de maturação, tamanho, sanidade e ausência de defeitos, e sanitizados em água clorada $\left(100 \mu \mathrm{L} \mathrm{L}^{-1}\right)$.

Aplicação de doses de 1-MCP em manga 'Tommy Atkins' sob temperatura ambiente

Os tratamentos testados foram: 1. aplicação de 1-MCP nas doses $0 ; 600 ; 1.200$ e $2.400 \mathrm{~nL} \mathrm{~L}^{-1}$, durante 14 horas, sob temperatura ambiente; e 2 . tempo de armazenamento: $0 ; 2 ; 4 ; 7 ; 9 ; 10$ e 11 dias, em temperatura ambiente $\left(26,7 \pm 2,0^{\circ} \mathrm{C}\right)$.

A aplicação de 1-MCP foi realizada em caixas herméticas de $0,186 \mathrm{~m}^{3}$, sem ventilação interna. No seu interior, os frutos foram dispostos a granel, em camada única.

As variáveis estudadas foram: a) perda de massa (\%): através da diferença entre a massa do fruto no dia da colheita e na data da avaliação; b) cor da casca na região vermelha e da polpa: obtidas em reflectômetro, através da média de duas leituras do ângulo de cor $\left({ }^{\circ} \mathrm{Hue}\right)$ realizadas em lados opostos da metade superior do fruto; c) firmeza da polpa $(\mathrm{N})$ : determinada pela resistência à penetração, utilizando penetrômetro manual modelo FT 327, com ponteira de $8 \mathrm{~mm}$ de diâmetro e realizando-se duas leituras, seguindo o critério descrito para a cor; d) teor de sólidos solúveis (SS, $\left.{ }^{\circ} \mathrm{Brix}\right)$ : obtido pela leitura em refratômetro digital (Instituto, 1985); e e) acidez titulável (AT, \% de ácido cítrico): por titulação com $\mathrm{NaOH}$ 0,1 M, segundo IAL (1985).

O delineamento experimental foi o inteiramente casualizado, em fatorial 4x7 (doses de 1-MCP x tempo de armazenamento), com 4 repetições, constituídas por 3 frutos.

Os dados foram submetidos à análise de variância e, quando os fatores isolados ou sua interação foram significativos, à regressão polinomial. Quando houve efeito significativo da interação, realizou-se o desdobramento das doses em cada tempo de armazenamento.

Avaliação de doses e do número de aplicações de 1-MCP em manga 'Tommy Atkins' durante 0 armazenamento refrigerado

Foram estudados dois tipos de tratamento: aplicação de 1MCP e tempo de armazenamento. No primeiro, foram testados doses de 1-MCP e número de aplicações: $0 \mathrm{~nL} \mathrm{~L}^{-1}$ (controle), uma aplicação de 900 $\mathrm{nL} \mathrm{L}^{-1}$, uma aplicação de $1.200 \mathrm{~nL} \mathrm{~L}^{-1}$ e duas aplicações de $900 \mathrm{~nL} \mathrm{~L}^{-1}$. Os frutos que receberam aplicação única foram tratados no dia da colheita. Para aqueles submetidos à segunda aplicação, esta foi conduzida no $14^{\circ}$ dia de armazenamento.

Os frutos foram avaliados com $0 ; 7 ; 15 ; 18 ; 20 ; 22 ; 25$ e 26 dias, sendo que até o $15^{\circ}$ dia estiveram armazenados sob refrigeração $(11,0$ $\pm 1,6^{\circ} \mathrm{C}$ e $88 \pm 7 \%$ UR), quando, então, foram transferidos para temperatura ambiente $\left(26,3 \pm 2,1^{\circ} \mathrm{C}\right.$ e $44 \pm 6 \%$ UR).

A aplicação de 1-MCP foi realizada nas caixas descritas anteriormente, mas providas de ventilação interna, onde os frutos foram acondicionados em caixas de papelão com capacidade para 4,0 kg. A exposição ao gás durou 12 horas e ocorreu no ambiente de refrigeração, com temperatura aproximada de $10^{\circ} \mathrm{C}$. Para o tratamento correspondente às duas aplicações de 1-MCP, a última foi realizada nas 12 horas finais que antecederam a retirada de todos os frutos para a condição de ambiente não refrigerado.

Todos os tratamentos foram compostos por 4 repetições formadas por 4 frutos cada uma, distribuídos em delineamento experimental inteiramente casualizado, em fatorial 4x8 (dose e número de aplicações de 1-MCP x tempo de armazenamento).
Os dados foram submetidos à análise de variância e, para os casos em que o tempo de armazenamento foi significativo, à regressão polinomial. As médias de doses e o número de aplicações de 1-MCP foram comparados pelo teste de Tukey $(\mathrm{P}<0,05)$. Quando houve efeito significativo da interação, realizou-se o desdobramento das doses e do número de aplicações de 1-MCP em cada tempo de armazenamento através de análise de regressão polinomial.

As variáveis analisadas foram aquelas listadas no experimento anterior.

\section{RESULTADOS E DISCUSSÃO}

\section{Aplicação de doses de 1-MCP em manga 'Tommy Atkins' sob temperatura ambiente}

A perda de massa foi influenciada separadamente pelos fatores tempo de armazenamento (Figura 1A) e doses de 1-MCP (Figura 1B). No $11^{\circ}$ dia de armazenamento, a perda de massa atingiu 10,7\% (Figura 1A). Nesta ocasião, foram observados, indistintamente entre as doses de 1-MCP, sinais de murcha em alguns frutos. Entretanto, as doses de $600 ; 1.200$ e $2.400 \mathrm{~nL} \mathrm{~L}^{-1}$ reduziram a perda de massa em 8,59; 6,42 e $7,83 \%$, respectivamente, comparado ao controle (Figura 1B). Essas diferenças podem representar redução de perdas no volume comercializado, uma vez que se utiliza a massa como referência nas operações de venda.

A maioria dos estudos sobre 1-MCP não relata efeito sobre a perda de massa. Entretanto, Jeong et al. (2002) observaram redução da perda de massa em abacates tratados com 1-MCP.

Os ângulos de cor da casca e da polpa variaram apenas com o tempo. Para o ${ }^{\circ} \mathrm{Hue}$ da casca, incrementos e reduções se alternaram (dados não apresentados), possivelmente devido à variabilidade natural entre frutos, influenciada, por exemplo, pela exposição da superfície aos raios solares e pela radiação solar disponível durante o desenvolvimento e a maturação.

Alguns estudos citam que o 1-MCP atrasa as mudanças de cor em abacate (Jeong et al., 2002), ameixa (Dong et al., 2002; Valero et al., 2003), maçã (Argenta et al., 2001) e manga (Hofman et al., 2001). Por outro lado, alguns destes autores relataram respostas distintas numa mesma espécie (Hofman et al., 2001; Jeong et al., 2002).

Abdi et al. (1998) ressaltaram que as mudanças na cor não são necessariamente dependentes de etileno e que a dependência estaria associada ao tipo de pigmento, ao tecido onde é sintetizado e à espécie vegetal. Assim, tratamentos que afetam o metabolismo do etileno podem ter respostas diferentes quanto às modificações na cor durante o amadurecimento.

As mudanças na cor da polpa foram mais evidentes que as da casca, sendo distinguíveis ao olho de um observador comum. O decréscimo linear no ${ }^{\circ} \mathrm{Hue}$ representou a evolução do amarelo para o laranja (dados não apresentados), independentemente da aplicação de 1-MCP.

A firmeza da polpa é a variável mais avaliada nos trabalhos sobre a ação do 1-MCP em frutos climatéricos. Neste estudo, a retenção da firmeza da polpa pelo 1-MCP foi observada no período entre o $4^{\circ} \mathrm{e} o$ $9^{\circ}$ dia, registrando-se a maior diferença entre as doses ao $7^{\circ}$ dia, quando a aplicação de $1.200 \mathrm{~nL} \mathrm{~L}^{-1}$ se mostrou mais eficiente (Figura 1C). Nessa data, os frutos tratados com $0 ; 600 ; 1.200$ e $2.400 \mathrm{~nL} \mathrm{~L}^{-1}$ apresentavam firmezas correspondentes, respectivamente, a 10,1;16,8;26,9 e 14,0 N. A partir do $9^{\circ}$ dia, as firmezas tornaram-se praticamente equivalentes. É possível que o efeito do 1-MCP tenha sido temporário e, a partir do $9^{\circ}$ dia, as taxas metabólicas tenham sido suficientemente rápidas para reverter o leve atraso anterior ou que o etileno disponível no meio tenha desencadeado as mudanças que resultaram no amaciamento.

É provável, ainda, que a perda de firmeza mais lenta, mesmo que temporariamente, nos frutos tratados com 1-MCP, possa ter reduzido a perda de massa, conforme citado anteriormente.

Alves et al. (2004) registraram resultados semelhantes mesmo testando doses inferiores às deste estudo. Embora a ligação do 1-MCP 

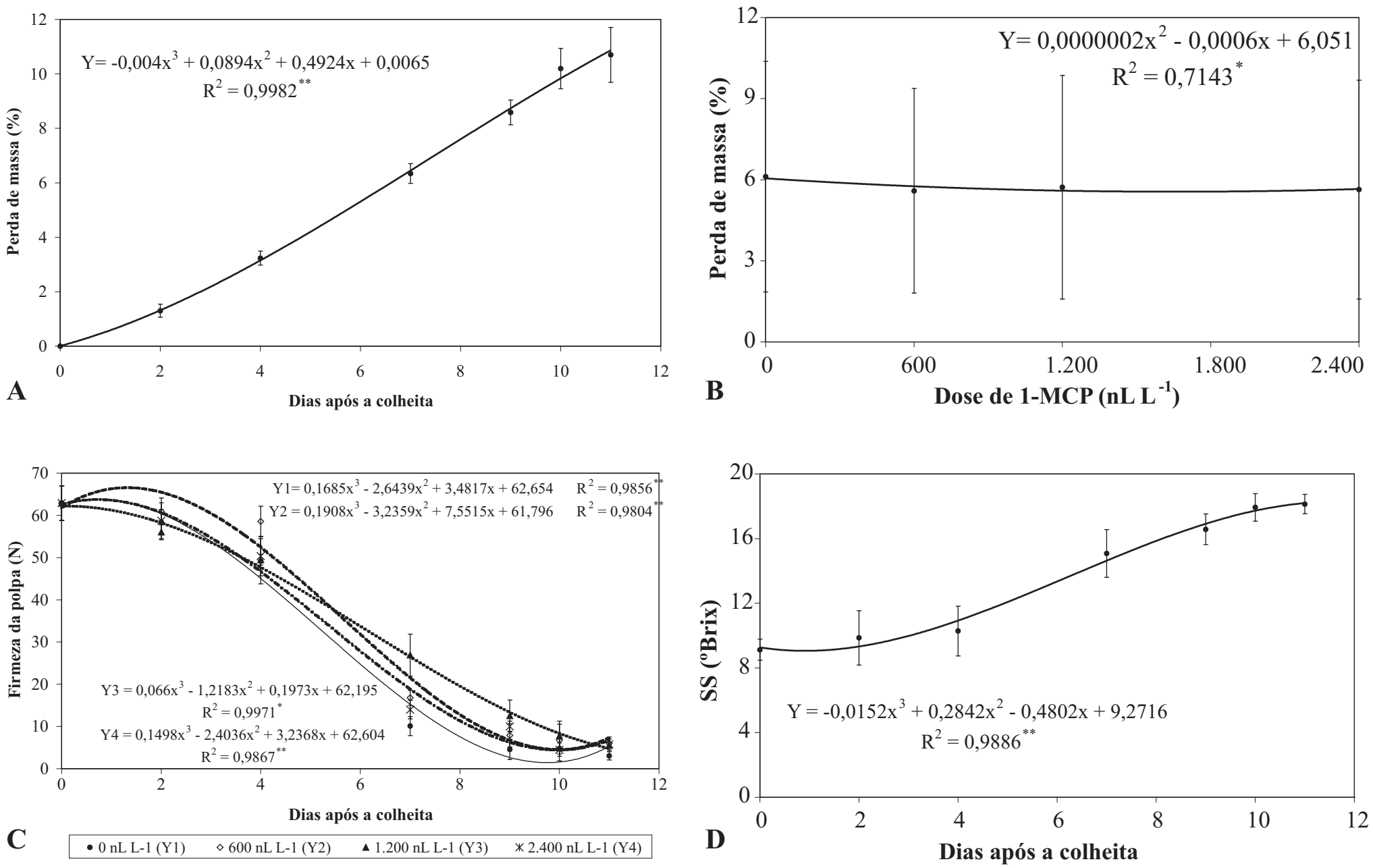

FIGURA 1 - Perda de massa (A e B), firmeza da polpa (C) e teor de sólidos solúveis - SS - (D) de manga 'Tommy Atkins' submetida à aplicação de doses de 1-MCP durante o armazenamento sob temperatura ambiente $\left(26,7 \pm 2,0^{\circ} \mathrm{C}\right)$. Em A e D, estão representados os valores médios dos tratamentos com 1-MCP e, em B, os valores médios do tempo de armazenamento. As barras verticais representam os desviospadrão.

ao receptor de etileno seja irreversível, as plantas recuperam sua sensibilidade ao fitormônio devido à renovação ou produção de novos receptores (Sisler \& Serek, 1997), retomando as taxas normais de amadurecimento.

A retenção da firmeza é o efeito mais amplamente observado nos estudos sobre utilização de 1-MCP em frutos (Fan et al., 2000; Argenta et al., 2001; Dong et al., 2002; Jeong et al., 2002; Valero et al., 2003). O atraso na perda de firmeza resultante da ação do 1-MCP é coerente com a hipótese de que é o etileno que desencadeia a atividade metabólica relacionada ao amaciamento (Dong et al., 2002; Jeong et al., 2002). O fato destaca a viabilidade da tecnologia, já que a manutenção da firmeza representa um dos fatores críticos que definem o período de conservação dos frutos (Yoshioka et al., 1994).

A partir da maior eficiência relativa da aplicação de $1.200 \mathrm{~nL} \mathrm{~L}^{-1}$, são sugeridos estudos com doses próximas deste valor, a fim de se verificar uma possível recomendação para manga.

O teor de SS e a AT não foram influenciados pelas doses de 1MCP. O ganho em SS acompanhou o amadurecimento normal da manga 'Tommy Atkins' (Figura 1D). A tendência de estabilização no teor de SS após o $9^{\circ}$ dia, associada a valores de firmeza ao redor de $10 \mathrm{~N}$, indica que os frutos de todos os tratamentos estavam maduros. A queda da AT, de 0,78 a 0,26\% de ácido cítrico, corrobora essa afirmação (dados não apresentados).

Hofman et al. (2001) registraram que a aplicação de 1-MCP em manga 'Kensington Pride' não afetava o teor de SS e a AT. Contudo, é importante destacar que as respostas dessas duas características à aplicação de 1-MCP são muito variáveis. Dependendo da espécie ou cultivar, podem ser verificados resultados distintos (Blankenship \& Dole, 2003)
Avaliação de doses e do número de aplicações de 1-MCP em manga durante 0 armazenamento refrigerado

Sob armazenamento refrigerado seguido de 11 dias em temperatura ambiente, foram observadas perdas crescentes de massa, independentemente das aplicações de 1-MCP (Figura 2A). O maior incremento ocorreu a partir do $15^{\circ}$ dia, quando os frutos foram transferidos para temperatura ambiente. No $25^{\circ}$ dia, os valores médios já eram de $11,7 \%$. Nesta ocasião, já se exibiam sinais de murcha em alguns frutos. Certamente, a temperatura mais alta e a menor umidade relativa aumentaram a suscetibilidade dos frutos à perda de água (Wills et al., 1998).

Considerando que as doses de 1-MCP aplicadas neste estudo foram mais próximas do que aquelas do primeiro, elas podem ter sido insuficientes para expressar efeitos diferenciais do inibidor de etileno sobre a perda de massa.

O ângulo de cor da casca não foi afetado pelas aplicações de 1-MCP. As variações ocorridas no período foram irregulares e numericamente pouco expressivas (desde 29,60 até 32,80), podendo ser atribuídas aos fatores já citados no experimento anterior. Para o ângulo de cor da polpa, a resposta foi semelhante à do primeiro estudo, revelando a mudança do amarelo para o laranja durante o amadurecimento da manga 'Tommy Atkins' (dados não apresentados).

Estas observações sugerem que as mudanças de cor da casca, associadas aos pigmentos vermelhos, e da polpa de manga não são influenciadas pelo 1-MCP nas doses e no número de aplicações testados. Abdi et al. (1998) e Valero et al. (2003) sugerem a existência de outros mecanismos, alheios à síntese de etileno, estimulando ou desencadeando essas mudanças.

A firmeza da polpa só começou a ser avaliada a partir do $20^{\circ}$ 

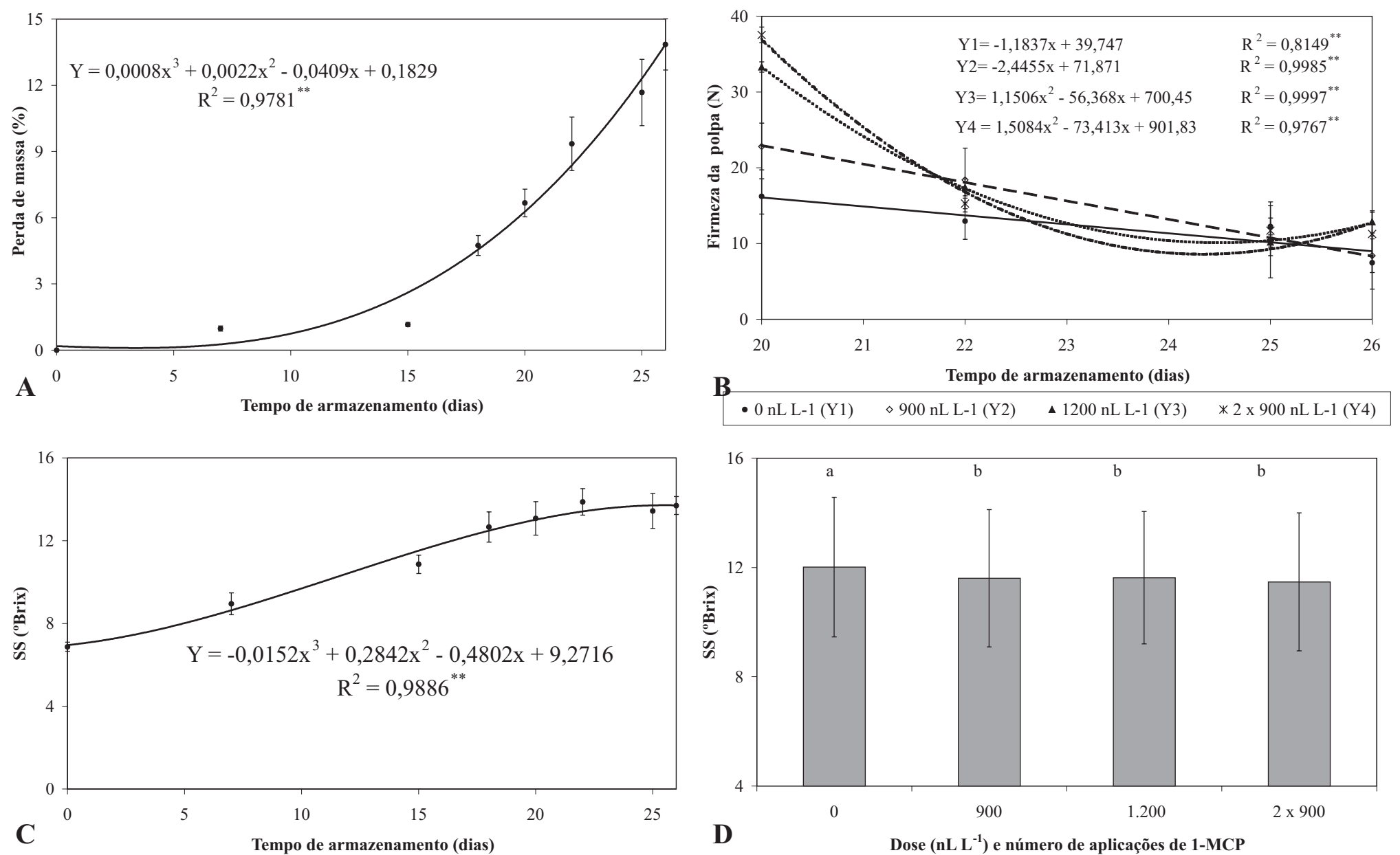

FIGURA 2 - Perda de massa (A), firmeza da polpa (B) e sólidos solúveis - SS - (C e D) de manga 'Tommy Atkins' submetida a diferentes doses e

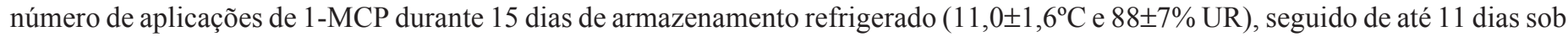
temperatura ambiente $\left(26,3 \pm 2,1^{\circ} \mathrm{C}\right.$ e $\left.44 \pm 6 \% \mathrm{UR}\right)$. Em A e C, estão representados os valores médios dos tratamentos com 1-MCP, e em D, dos tempos de armazenamento. Médias seguidas da mesma letra, em D, não diferem pelo teste de Tukey $(\mathrm{P}<0,05)$. As barras verticais representam os desvios-padrão.

dia, quando a resistência dos frutos à penetração foi compatível com a faixa de leitura do penetrômetro manual.

Aos 20 dias, os valores de firmeza da polpa indicavam que o amaciamento nos frutos tratados com 1-MCP foi mais lento e dependente da concentração e do número de aplicações (Figura 2B). Naquela ocasião, os valores de firmeza do controle e dos frutos que receberam uma aplicação de $900 \mathrm{~nL} \mathrm{~L}^{-1}$, uma aplicação de $1.200 \mathrm{~nL} \mathrm{~L}^{-1}$ e duas aplicações de $900 \mathrm{~nL} \mathrm{~L}^{-1}$ foram, respectivamente: 16,2; 22,8; 33,3 e 37,5 N. Aos 22 dias, as diferenças diminuíram, registrando-se, ainda, menor firmeza nos frutos do controle. A partir do $25^{\circ}$ dia, a resposta não se manteve, à semelhança do que foi verificado no experimento anterior.

$\mathrm{O}$ atraso no amaciamento resultante da ação do 1-MCP é coerente com a hipótese de que é o etileno que desencadeia a atividade metabólica relacionada ao processo (Jeong et al., 2002). Por sua vez, efeitos temporários devem-se à maior taxa de renovação ou produção de novos receptores de etileno numa determinada espécie ou tecido (Sisler \& Serek, 1997).

O teor de SS aumentou até o $22^{\circ}$ dia, quando atingiu $13,9^{\circ}$ Brix, mantendo-se estável até o final do estudo (Figura $2 \mathrm{C}$ ). No $25^{\circ}$ dia, quando a firmeza da polpa era de aproximadamente $10 \mathrm{~N}$, os frutos de todos os tratamentos estavam prontos para o consumo in natura.

As aplicações de 1-MCP resultaram em acúmulo relativo de SS levemente menor (Figura 2D). Entretanto, as diferenças foram limitadas a $0,5^{\circ}$ Brix, não podendo ser distinguidas pelo consumidor. Desta forma, não incorreriam em rejeição ou desprestígio dos frutos tratados.

Apesar de restritas, as respostas distintas à aplicação de 1MCP sobre SS nos dois experimentos reforçam a idéia de que o papel do etileno na conversão de amido a açúcares, componente predominante dos SS, ainda não está claro. Segundo Blankenship \& Dole (2003), apenas alguns trabalhos registram efeitos do 1-MCP nesta conversão, mas os resultados podem variar entre espécies, cultivares, condições de crescimento e estádio de maturação.

A resposta da AT foi semelhante à obtida no primeiro experimento, observando-se decréscimo de 1,15 a $0,19 \%$ de ácido cítrico (dados não apresentados). É importante destacar o momento da transferência dos frutos da refrigeração para condições de temperatura ambiente como determinante da taxa de degradação dos ácidos orgânicos.

Porém, estudos realizados por Cocozza (2003) informaram que $500 \mathrm{~nL} \mathrm{~L}^{-1}$ de 1-MCP limitaram a redução da AT, mas aceleraram as mudanças na cor e no amaciamento da manga.

Segundo Pelayo et al. (2003), normalmente, os estudos com 1MCP relatam desde efeitos relevantes até alguns menos notórios. Aqueles mais marcantes dificilmente são mascarados pela variabilidade amostral, ao contrário dos efeitos mais suaves. É provável que as condições ambientais, os fatores pré-colheita e o manuseio pós-colheita influenciem na sensibilidade de alguns frutos à ação do etileno e, por conseguinte, à do 1-MCP.

\section{CONCLUSÕES}

1. Aplicações pós-colheita de 1-MCP em manga 'Tommy Atkins' afetam essencialmente a firmeza da polpa, sendo a aplicação de 1.200 $\mathrm{nL} \mathrm{L}{ }^{-1}$ a mais eficiente no retardo do amaciamento.

2. A realização de uma aplicação de $1.200 \mathrm{~nL} \mathrm{~L}^{-1}$ ou duas de 900 $\mathrm{nL} \mathrm{L}{ }^{-1}$, sendo a primeira no início da refrigeração e a segunda nas últimas doze horas, resulta em efeitos praticamente equivalentes. Porém, o tratamento no início da refrigeração representa menor interferência nas operações pós-colheita. 


\section{REFERÊNCIAS}

ABDI, N.; McGLASSON, W.B.; HOLFORD, P.; WILLIAMS, M.; MIZRAHI, Y. Responses of climateric and suppressed-climateric plums to treatment with propylene and 1-methylcyclopropene. Postharvest Biology and Technology, Amsterdam, v.14, n.1, p.2939, 1998.

IBGE. Produção agrícola municipal: área cultivada com manga por grandes regiões e unidades da federação. Disponível em $<$ http:// www.ibge.gov.br>. Acesso em: 19 ago. 2005.

ALVES, R.E.; FILGUEIRAS, H.A.C.; ALMEIDA, A. de S.; PEREIRA, M.E.C.; COCOZZA, F. del M.; JORGE, J.T. Postharvest ripening of 'Tommy Atkins' mangoes in two maturation stages treated with 1MCP. Acta Horticulturae, Brugg, n.645, p.627-632, 2004.

ARGENTA, L.C; MATTHEIS, J.; FAN, X. Retardamento da maturação de maçãs 'Fuji' pelo tratamento com 1-MCP e manejo da temperatura. Revista Brasileira de Fruticultura, Jaboticabal, v.23, n.2, p.270273, 2001.

BLANKENSHIP, S.M.; DOLE, J.M. 1-Methylcyclopropene: a review. Postharvest Biology and Technology, Amsterdam, v.28, n.1, p.1-25, 2003.

COCOZZA, F. del M. Maturação e conservação de manga 'Tommy Atkins' à aplicação pós-colheita de 1-metilciclopropeno. 2003. 198f Tese (Doutorado em Tecnologia de Pós-Colheita) - Faculdade de Engenharia Agrícola, Universidade Estadual de Campinas, Campinas, 2003.

COCOZZA, F. del M.; JORGE, J.T.; ALVES, R.E.; FILGUEIRAS, H.A.C.; PEREIRA, M.E.C. Respiration rate and chemical characteristics of cold stored 'Tommy Atkins' mangoes influenced by 1-MCP and modified atmosphere packaging. Acta Horticulturae, Brugg, n.645, p.645-650, 2004.

DONG, L.; LURIE, S.; ZHOU, H.W. Effect of 1-methylcyclopropene on ripening of 'Canino' apricots and 'Royal Zee' plums. Postharvest Biology and Technology, Amsterdam, v.24, n.2, p.135-145, 2002.

FAN, X.; ARGENTA, L.; MATTHEIS, J.P. Inhibition of ethylene action by 1 -methylcyclopropene prolongs storage life of apricots. Postharvest Biology and Technology, Amsterdam, v.20, n.2, p.135$142,2000$.
JEONG, J.; HUBER, D.J.; SARGENT, S.A. Influence of 1methylcyclopropene (1-MCP) on ripening and cell-wall matrix polysaccharides of avocado (Persea americana) fruit. Postharvest Biology and Technology, Amsterdam, v.25, n.3, p.241-256, 2002.

HARRIS, D.R.; SEBERRY, J.A.; WILLS, R.B.H.; SPOHR, L.J. Effect of fruit maturity on efficiency of 1-methylcyclopropene to delay the ripening of bananas. Postharvest Biology and Technology, Amsterdam, v.20, n.3, p.303-308, 2000.

HOFMAN, P.J.; JOBIN-DECOR, M.; MEIBURG, G.F.; MACNISH, A.J.; JOYCE, D.C. Ripening and quality responses of avocado, custard apple, mango and papaya fruit to 1-methylcyclopropene. Australian Journal of Experimental Agriculture, Victoria, v.41, p.567-572, 2001.

INSTITUTO ADOLFO LUTZ. Normas analíticas, métodos químicos e físicos para análise de alimentos. São Paulo, 1985. v.1, 371p.

PELAYO, C.; VILAS-BOAS, E.V. de B.; BENICHOU, M.; KADER, A.A. Variability in responses of partially ripen bananas to 1methylcyclopropene. Postharvest Biology and Technology, Amsterdam, v. 28, n.1, p.75-85, 2003.

SISLER, E.C.; SEREK, M. Inhibitors of ethylene responses in plants at the receptor level: recent developments. Physiologia Plantarum, Copenhagen, v.100, n.3, p.577-582, 1997.

VALERO, D.; MARTÍNEZ-ROMERO, D.; VALVERDE, J.M.; GUILLÉN, F.; SERRANO, M. Quality improvement and extension of shelf life by 1-methylcyclopropene in plum as affected by ripening stage at harvest. Innovative Food Science and Emerging Technologies, Amsterdam, v.4, n.2, p.339-348, 2003.

VALEXPORT. Há 17 anos unindo forças para o desenvolvimento do Vale do São Francisco e da fruticultura brasileira. Petrolina, 2005. $17 \mathrm{p}$.

WILLS, R.; McGLASSON, B.; GRAHAM, D.; JOYCE, D. Postharvest: an introduction to the physiology $\&$ handling of fruit, vegetables $\&$ ornamentals. $4^{\text {th }}$ ed. Wallingford: New South Wales University Press, 1998. 262p.

YOSHIOKA, H.; KASHIMURA, Y.; KANEKO, K. Solubilization and distribution of neutral sugar residues derived from polyuronides during the softening in apple fruit. Journal of the Japanese Society of Horticultural Science, Kyoto, v.63, n.1, p.173-182, 1994. 